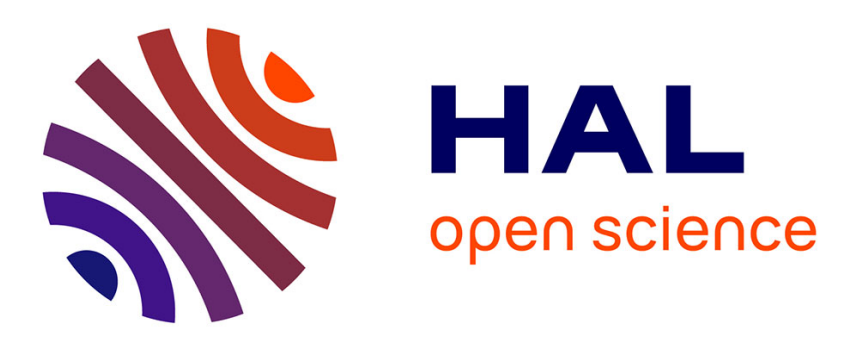

\title{
A 3-D Strong-Coupled Electromagnetic-Thermal Model for HTS Bulk and Its Uses to Study the Dynamic Characteristics of a Linear HTS Maglev Bearing Wenjiao Yang, Loic Queval, Guangtong Ma, Changqing Ye, Li Gang, Tianyong Gong
}

\section{To cite this version:}

Wenjiao Yang, Loic Queval, Guangtong Ma, Changqing Ye, Li Gang, et al.. A 3-D Strong-Coupled Electromagnetic-Thermal Model for HTS Bulk and Its Uses to Study the Dynamic Characteristics of a Linear HTS Maglev Bearing. IEEE Transactions on Applied Superconductivity, 2020, 30 (6), pp.3602814. 10.1109/TASC.2020.2982879 . hal-03093941

\section{HAL Id: hal-03093941 https://hal.science/hal-03093941}

Submitted on 4 Jan 2021

HAL is a multi-disciplinary open access archive for the deposit and dissemination of scientific research documents, whether they are published or not. The documents may come from teaching and research institutions in France or abroad, or from public or private research centers.
L'archive ouverte pluridisciplinaire HAL, est destinée au dépôt et à la diffusion de documents scientifiques de niveau recherche, publiés ou non, émanant des établissements d'enseignement et de recherche français ou étrangers, des laboratoires publics ou privés. 
Author's postprint (i.e. final draft post-refereeing) published in the IEEE Transactions on Applied Superconductivity (Sept. 2020).

(C)2020 IEEE. Personal use of this material is permitted. Permission from IEEE must be obtained for all other users, including reprinting/ republishing this material for advertising or promotional purposes, creating new collective works for resale or redistribution to servers or lists, or reuse of any copyrighted components of this work in other works.

DOI: http://doi.org/10.1109/TASC.2020.2982879

URL: https://ieeexplore.ieee.org/document/9050466

Cite: W.-J. Yang, L. Quéval, G.-T. Ma, C.-Q. Ye, G. Li, T.-Y. Gong, “A 3-D strong-coupled electromagnetic-thermal model for HTS bulk and its uses to study the dynamic characteristics of a linear HTS maglev bearing,” IEEE Trans. on Applied Superconductivity, vol. 30, no. 6, id. 3602814, Sept. 2020. 


\title{
A 3-D Strong-coupled Electromagnetic-Thermal Model for HTS Bulk and its Uses to Study the Dynamic Characteristics of a linear HTS Maglev Bearing
}

\author{
Wenjiao Yang, Loic Quéval, Guangtong Ma, Changqing Ye, Gang Li, Tianyong Gong
}

\begin{abstract}
Thermal effect will greatly affect the engineering performance of high temperature superconductors (HTSs) due to its strong dependence of electromagnetic parameters upon the local temperature. To advance the understanding of such thermal effect, a validated three-dimensional (3-D) strong-coupled electromagnetic-thermal model for HTS bulk was established in commercial finite element software COMSOL, which ensures the easy access and universality of the model. $\operatorname{Jc}(B, T)$ was employed to reflect both magnetic field and thermal field dependences of HTS in this model. In addition, the thermal transient equation and convective boundary condition were employed with experimentally measured HTS thermal conductivity and heat capacity to describe the thermal flux exchange between HTS and cryogenic medium. As an example of application, the established electromagnetic-thermal model was tailored to study the dynamic characteristics of a linear HTS magnetic levitation (maglev) bearing. The methodologies to numerically study the dynamic response of the linear HTS maglev bearing under free vibration state and typical operating excitations, e.g. earthquake, track irregularity and crosswind, were put forward in this paper. The influences of field cooling height, pre-load and ambient temperature, were also studied and promising methods to improve the system stability were put forward according to the obtained conclusions. The above results are reasonable and keep in concert with former experimental and theoretical studies. Moreover, some results which are inaccessible in the 2-D models, for instance, the thermal field distribution inside HTS bulk, can also be obtained due to the versatility of 3-D model. To conclude, the established HTS electromagnetic-thermal model could serve as a flexible and extensible simulation tool to study various applications of HTS bulk. Besides the application in linear HTS maglev bearing, which is systematically studied in this paper, other potential applications such as thermal analysis of HTS bulk in pulse magnetization process, HTS bulkbased electrical machines, can also be expected in future work.
\end{abstract}

Index Terms - High temperature superconductors (HTSs); Permanent magnet (PM); Magnetic levitation (maglev); Dynamic Characteristics; Strong-coupled multi-physical model

\section{INTRODUCTION}

ince the birth of high temperature superconductor (HTS) Sbulk, a large number of engineering applications or conceptual designs of HTS, such as linear or rotary HTS magnetic levitation (maglev) bearings [1-10] and portable high field magnets [11,12], have emerged. A comprehensive review of bulkbased applications can be found in [13]. No matter these applications are based on the flux pinning effect or the Meissner effect, the engineering performance of them are greatly affected by the thermal effect due to the strong dependence of HTS's electromagnetic parameters upon the local temperature. Numerical modelling techniques are essential and effective to understand and predict the performance of HTS bulk in these applications due to the challenges of experimental conditions or budget sometimes. Also, it is a key ingredient for the optimization of HTS devices [14]. In past years much effort has been made to the modelling of the HTS bulk, however, most of them only took magnetic field dependence of critical current density $J_{c}(\mathbf{B})$ into consideration with thermal effect excluded [15-20], although being accurate enough for their own study. As a result, further development of numerical modelling techniques, which could consider both magnetic field and thermal field dependences of critical current density comprehensively, is needed.

A three-dimensional(3-D) strong-coupled electromagneticthermal model for HTS bulk was established consequently in this paper. The effectiveness of this model was validated by the comparison between the calculated and experimentally measured hysteresis loop of levitation force. The commercial finite element software COMSOL was selected as the modelling tool since it ensures the easy access and universality of the model. On the basis of this model, various studies, for instance the thermal analysis of HTS bulk in pulse magnetization process

Power, Southwest Jiaotong University, Chengdu 610031, China (e-mail: gtma@swjtu.edu.cn).

Loic Quéval is with the the Group of Electrical Engineering-Paris, CNRS UMR 8507, CentraleSupélec, UPSud, UPMC, Gif-sur-Yvette 91192, France (email: loic.queval@gmail.com) 
[21,22], HTS bulk-based electrical machines [23], could be performed to understand and predict the performance of these applications with proper modifications. Considering the systematicness and completeness of the paper, the emphasis of this paper is to apply this electromagnetic-thermal model in the study of dynamic characteristics of a linear HTS maglev bearing. It was further coupled with motion equations to study the dynamic characteristics of the linear HTS maglev bearing as an application example in this paper. Other applications of this model could be exploited in future work.

The linear HTS maglev bearing is regarded as one of the promising candidates for future high-speed ground transportation or magnetic launch due to its contactless operation, passive stabilization, lighter and more compact cryogenic system. Nevertheless, during the operation of linear HTS maglev bearing, the external factors, such as crosswind, earthquake, and the inherent irregularity of guideway caused by fabrication and installation error, will inevitably make it unable to operate in ideal state, resulting in the oscillation of levitation and guidance forces. Stable levitation force and sufficient guidance force are the premise of the stable operation of linear HTS maglev bearing. The oscillation of levitation and guidance forces will consequently probably affect the stability even safety. The dynamic characteristics is therefore essential for the linear HTS maglev bearing and must be well understood to ensure stability and safety.

Previous studies on the dynamic characteristics of HTS maglev systems mainly relied on two methods. One is the experimental measurement on dynamics of HTS maglev bearing and the other is the analytical simulation based on approximate fitting of its force-displacement relationship. Shortly after the discovery of HTS maglev, the nonlinearity of the vibration of HTS maglev system [24], the levitation drift phenomenon [25] and the existence of natural frequency $[26,27]$ were found experimentally. Further studies on the factors that affect levitation drift [28-31], and the relationship between natural frequency and levitation gap as well as the mass of levitated body [32] were also performed experimentally afterwards. Besides, differing from the above studies, the rotational dynamics of a discshaped permanent magnet (PM) rotor levitated over a high temperature superconductor was studied experimentally in [33].

On the other hand, analytical methods based on approximate fitting of the force-displacement relationship were employed to study the dynamics characteristics, e.g. bifurcation, multi-fractality [34,35] and vertical stability [36]. In view of the free vibration and low speed operation, the effects of field cooling height, working height, load weight and their contributions on the resonance frequency, dynamic stiffness and damping coefficient of the linear HTS maglev bearing system, as well as the lateral recoverability of linear bearing, have been studied both experimentally and analytically in [37-39].

In addition, some numerical studies on the dynamic characteristics of HTS maglev system have emerged in recent years. The natural frequency, damping characteristics, energy loss, levitation drift, were studied using a quasi-three-dimensional model based on T-formulation in [40-42]. A 3-D numerical model for a maglev system consisting of a square PM and a cylindrical HTS was established in [43], in which the vertical vibration characteristics have been studied. Differing from previous studies, the temperature rise in HTS has been taken into consideration in this model. However, the analytical method was used to calculate the magnetic field of PM. Analytical method is straightforward but unable to consider the influence of ferromagnetic materials on the magnetic field which is common in PM guideway. More importantly, the weak coupling was used in this model between the electromagnetic and thermal fields, i.e. the electromagnetic field module and the thermal field module are calculated independently. Lateral stability was not involved in this study either. A 2-D numerical model based on vector potential A- $v$ method was built in [44], in which the effects of material-related parameters $n$ and the initial speed on the vibration characteristics of HTS maglev system composed of HTS and simplified PM guideway were studied. Analytical method to calculate the magnetic field of PMs was also employed in this model, which is of poor extendibility since different equations are required for different geometries. The magnetic field dependence of critical current density and thermal effect of HTSs were also neglected in the model. This work was recently improved with thermal effect and rotational effect considered in [45].

The above studies have found some phenomena differing from traditional vibration problems, e.g. levitation drift. The obtained results are of important guiding significance for understanding the vibration characteristics of HTS maglev systems. For all that, the existing research methods for the vibration characteristics of HTS maglev system are mainly experimental tests. Though being straightforward and precise, it is difficult to analyze the strong coupling between the various physical fields in experimental tests. On the other hand, theoretical studies generally simplify the HTS maglev system as a singledegree-of-freedom linear damping system analytically with approximate fitting of HTS force-displacement relationship. Thermal effects and non-linear high-order components of vibration were generally ignored. Only qualitative analysis on the vibration characteristics can be obtained through these theoretical studies. Even if there are few numerical models considering the thermal effect, only the weak coupling between the superconducting magnetic field and thermal field was implemented, and only the simple vertical vibration condition was considered. Additionally, the response of HTS maglev system under external excitations is rarely investigated to date. The dynamic characteristics of HTS maglev systems needs to be further advanced.

In order to overcome the present research limitations, the established electromagnetic-thermal model was used aiming at advancing the understanding of the dynamic characteristics of HTS maglev system. At the same time, the dynamic responses of a linear HTS maglev bearing under typical excitations for its application, i.e. earthquake, track irregularity and crosswind, were calculated systematically with and without thermal effect to study the influence of thermal effect. Furthermore, this model was used to find the way to improve the system stability. The 
influences of field cooling height, pre-load and ambient temperature were studied, and potential methods to suppress vibration so as to improve system stability were put forward according to the obtained conclusions.

\section{MODELLING}

\section{A. Electromagnetic model}

In the HTS maglev system, the stable levitation results from the electromagnetic interaction between HTS and the PM guideway. With the HTS assembly and PM assembly modeled with $\mathbf{H}$ formulation and magnetostatic $\mathbf{A}$ formulation respectively, an indirect coupling [46,47] is obtained by taking the sum of external field $\mathbf{H}_{\text {ext }}$ from PM assembly model and selffield $\mathbf{H}_{\text {self }}$ as the boundary condition for HTS assembly model.

\section{1) PM assembly model}

The magnetic field generated by PM can be calculated analytically or numerically. Analytically it is difficult to calculate the field of commonly used ferromagnets in PM guideway. $\mathrm{Nu}-$ merically, it is more concise and comprehensive for any geometry and structure. Therefore, here the magnetic field of the PM is solved by COMSOL numerically in this work. A remanent magnetic flux density $B_{\mathrm{r}}=1.27 \mathrm{~T}$ has been found by a trial-anderror process, which minimizes the difference between the measured data and the PM assembly model.

\section{2) HTS assembly model}

\section{a) $\quad H$ formulation}

The $\mathbf{H}$ formulation is generally adopted to model the HTS as its well-approved flexibility in COMSOL [48-52] and it was also implemented in this work. For HTS assembly model, the whole field including HTS domain and air domain is governed by Faraday's law within the quasistatic approximation,

$$
\nabla \times \mathbf{E}=-\mu \frac{\partial \mathbf{H}}{\partial t},
$$

where $\mathbf{H}$ and $\mathbf{E}$ represent the magnetic field strength and electrical field strength.

$$
\begin{gathered}
\mathbf{J}=\nabla \times \mathbf{H}, \\
\mathbf{E}=\rho \mathbf{J}, \\
\mathbf{B}=\mu \mathbf{H},
\end{gathered}
$$

Where $\rho$ represents the resistivity of the material. The governing equation of $\mathbf{H}$ formulation, as shown in (5), could be obtained by substituting above constitutive relationships into (1).

$$
\nabla \times(\rho \nabla \times \mathbf{H})=-\mu \frac{\partial \mathbf{H}}{\partial t},
$$

This equation can be solved in COMSOL using the general form PDE interface with $\rho$ differing in HTS domain and air domain:

$$
\begin{aligned}
\rho_{a i r} & =1 \Omega m, \\
\rho_{s c}(\mathbf{J}, \mathbf{B}) & =\frac{E_{c}}{J_{c}(\mathbf{B})}\left|\frac{\mathbf{J}}{J_{c}(\mathbf{B})}\right|^{n-1} .
\end{aligned}
$$

The nonlinearity of the HTS is expressed by the power law (7), where $E_{c}$ is the critical current criterion and $n$ is the material-related parameter. The magnetic field dependence of critical current density $J_{c}(\mathbf{B})$ is taken into account by

$$
J_{c}(\mathbf{B})=\frac{J_{c 0} \cdot B_{0}}{B_{0}+|\mathbf{B}|}
$$

where $J_{c 0}$ is the critical current density in the absence of magnetic field, while $B_{0}$ is material parameter.

\section{b) Boundary Conditions}

The modeling methodology of indirect coupling implies that the PM assembly model was calculated firstly and then the HTS assembly model are calculated with boundary conditions that include the field of PM. Another advantage of indirect coupling is the avoidance of moving mesh caused by relative motion between HTS and PM guideway. Taking place of that, the relative movement is achieved through the way to define the coordinate of HTS in the boundary conditions as a function of time $x(t)$, $y(t)$, and $z(t)$. The boundary conditions of HTS assembly are consequently given as follows,

$$
\mathbf{H}(t)=\mathbf{H}_{\text {ext }}(x(t), y(t), z(t))+\mathbf{H}_{\text {self }}(x(t), y(t), z(t)),
$$

in which $\mathbf{H}_{\text {ext }}$ and $\mathbf{H}_{\text {self }}$ respectively represent the magnetic field from the PM and the self-field generated by the HTS. Note that the impact of HTS on the coercive of PM is assumed to be weak enough to be neglected. The self-field of the HTS is obtained by means of Biot-Savart's law, in which the self-field generated by the HTS at any space point $\mathrm{P}\left(x_{0}, y_{0}, z_{0}\right)$ is

$$
\begin{aligned}
& H_{\text {self }, x}=\frac{1}{4 \pi} \int_{s c} \frac{J_{y}\left(z_{0}-z\right)-J_{z}\left(y_{0}-y\right)}{\left(\left(x_{0}-x\right)^{2}+\left(y_{0}-y\right)^{2}+\left(z_{0}-z\right)^{2}\right)^{\frac{3}{2}}} d_{x} d_{y} d_{z}, \\
& H_{\text {self }, y}=\frac{1}{4 \pi} \int_{s c} \frac{J_{z}\left(x_{0}-x\right)-J_{x}\left(z_{0}-z\right)}{\left(\left(x_{0}-x\right)^{2}+\left(y_{0}-y\right)^{2}+\left(z_{0}-z\right)^{2}\right)^{\frac{3}{2}}} d_{x} d_{y} d_{z}, \\
& H_{\text {self }, z}=\frac{1}{4 \pi} \int_{s c} \frac{J_{x}\left(y_{0}-y\right)-J_{y}\left(x_{0}-x\right)}{\left(\left(x_{0}-x\right)^{2}+\left(y_{0}-y\right)^{2}+\left(z_{0}-z\right)^{2}\right)^{\frac{3}{2}}} d_{x} d_{y} d_{z} .
\end{aligned}
$$

The levitation force $F_{z}$ and guidance force $F_{x}$ could be obtained by integrations shown in (11) and (12).

$$
\begin{aligned}
& F_{z}=\iiint_{S C}\left(J_{\boldsymbol{x}} \cdot B_{\boldsymbol{y}}-J_{\boldsymbol{y}} \cdot B_{\boldsymbol{x}}\right) d_{x} d_{y} d_{z} \\
& F_{x}=\iiint_{S C}\left(J_{\boldsymbol{y}} \cdot B_{z}-J_{z} \cdot B_{y}\right) d_{x} d_{y} d_{z}
\end{aligned}
$$

Note that this electromagnetic model has been extensively validated in both zero field cooling and field cooling conditions, for both vertical and lateral movement sequences in our former work [47].

\section{B. Electromagnetic-thermal model}

\section{1) Mathematical formulations}

For the electromagnetic-thermal model, the temperature dependence of $J_{c}$ is included by replacing $J_{c 0}$ in (8) by[53]

$$
J_{c 0}(T)=J_{c 0} \frac{T_{c}-T}{T_{c}-T_{0}},
$$

where $T$ is temperature; $T_{0}$ indicates the temperature at which $J_{c 0}$ has been determined (usually $77 \mathrm{~K}$ ), and $T_{c}=92 \mathrm{~K}$ is represented as the critical temperature of HTS. 
Thermal transient (14) is employed to describe the thermal flux exchange between the HTS and the liquid nitrogen with joule heat $Q$ as the source term,

$$
\begin{gathered}
k \cdot\left(\frac{\partial^{2} T}{\partial x^{2}}+\frac{\partial^{2} T}{\partial y^{2}}+\frac{\partial^{2} T}{\partial z^{2}}\right)-c \cdot\left(\frac{\partial T}{\partial t}\right)=-Q, \\
Q=\mathbf{J} \cdot \mathbf{E},
\end{gathered}
$$

where $k$ and $c$ respectively represent thermal conductivity and heat capacity for per unit volume of HTS bulk. Both of them being temperature-dependent, their expressions are obtained from experiments with $\mathrm{YBaCuO}$ HTS bulk in [54].

$$
\begin{gathered}
k=7.90506 \times 10^{-6} T^{3}-2.17 \times 10^{-3} T^{2}+0.17407 T- \\
0.21246(\mathrm{~W} /(\mathrm{m} \cdot \mathrm{K})) \\
c=73.75 T^{2}+5599.78 T+87669.311\left(\mathrm{~J} /\left(\mathrm{m}^{3} \cdot \mathrm{K}\right)\right)(17)
\end{gathered}
$$

For the boundary condition, we consider only convective heat transfer with

$$
\mathrm{k} \cdot\left(\frac{\partial T}{\partial n}\right)+h \cdot\left(T-T_{\mathrm{at}}\right)=0,
$$

where $h=400 \mathrm{~W} /\left(\mathrm{m}^{2} \cdot \mathrm{K}\right)[43][53]$ is the convective heat transfer coefficient. $T_{a t}$ is the ambient temperature. Except otherwise defined, $T_{a t}=77 \mathrm{~K}$ [45], which means the system works in liquid nitrogen at atmosphere without any other cooling measurement. It worth noting that, for the electromagnetic-thermal model, the $\mathbf{H}$ formulation is still implemented using general form PDE interface, while the thermal transient equation and heat convection equation are implemented using coefficient form PDE interface of COMSOL.

\section{2) Model validation}

To check the effectiveness of the electromagnetic-thermal model, we measured the hysteretic loop of levitation force $F_{z}$ on a $\mathrm{YBaCuO}$ bulk during zero field cooling sequence [55], which is commonly used to evaluate the levitation performance SMB, with a self-developed testing system[56]. The employed experiment system was illustrated in Fig. 1. In the measurement, the bulk was cooled with liquid nitrogen at $77 \mathrm{~K}$ at a distance of $100 \mathrm{~mm}$ above the center of the PM, then the bulk was moved vertically (z-direction) downward until the gap between the bulk and the PM is $6 \mathrm{~mm}$, after that the bulk was reversed to its initial position. This sequence was used for validation. The speed of HTS bulk is set as $1 \mathrm{~mm} / \mathrm{s}$ to create a quasistatic movement. Same experiment procedure was simulated with the methodology described above. The parameters used in the model are summarized in Table I, and the following parameters remain unchanged during subsequent modeling and calculation.

The result was plotted together with the measured data in Fig. 2. The result without thermal effect [47] was also shown in Fig. 2. It can be seen that both simulated curves are able to well reproduce the measured $F_{z}$ in terms of magnitude and tendency, leading to a good agreement with the hysteretic loop. Note that in ZFC sequence the HTS bulk is in quasistatic state. Little heat was generated in this sequence, thus the results calculated with and without thermal effect are almost same.

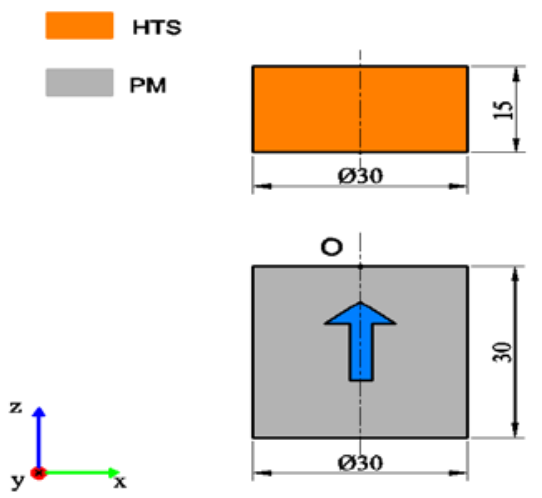

Fig. 1. Experimental system employed in the measurement. The system consists of a cylindrical bulk and a cylindrical PM. The arrow indicates the magnetization direction of PM.

TABLE I

PARAMETERS FOR ELECTROMAGNETIC-THERMAL MODEL

\begin{tabular}{cc}
\hline \hline Parameters & VALUE \\
& \\
\hline$B_{r}$ & $1.27 \mathrm{~T}$ \\
$\mu$ & $4 \pi \times 10^{-7} \mathrm{H} / \mathrm{m}$ \\
$n$ & 21 \\
$E_{c}$ & $1 \times 10^{-4} \mathrm{~V} / \mathrm{m}$ \\
$J_{c 0}$ & $0.55 \times 10^{8} \mathrm{~A} / \mathrm{m}^{2}$ \\
$B_{0}$ & $92 \mathrm{~K}$ \\
$T_{c}$ & $77 \mathrm{~K}$ \\
$T_{0}$ & $400 \mathrm{~W} /\left(\mathrm{m}^{2} \cdot \mathrm{K}\right)$ \\
$h$ &
\end{tabular}

It can be concluded that the above numerical model is a reliable tool to model the electromagnetic interaction between HTS and PM, and a crucial premise for further dynamic research.

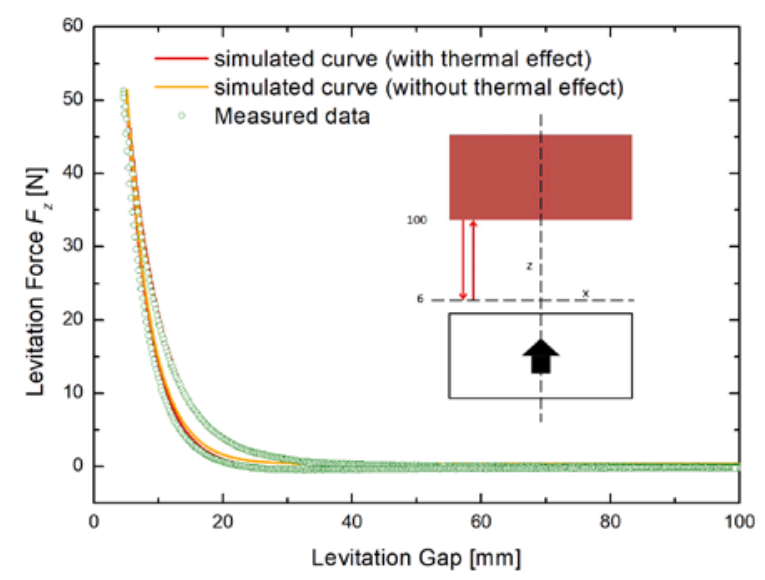

Fig. 2. Measured (green dot) and simulated levitation forces with (red line) and without (orange line) thermal effect during zero field cooling sequence. The inset illustrates the zero field cooling sequence, in which arrows indicate the magnetization direction of PM.

\section{3) Electromagnetic-thermal-mechanical model}

As it is mentioned before, this paper focuses on the study the dynamic characteristics of a linear HTS maglev bearing as an application example of this electromagnetic-thermal model. Thus Newton's second law is employed for both the vertical and 
lateral directions. Note that $y$ is assumed as the running direction of the linear bearing. The displacement caused by the vibration in this direction was ignored in this work.

$$
\begin{gathered}
m \ddot{z}_{r}-F_{z}+m g=F_{e, z}, \\
m \ddot{x}_{r}+F_{x}=F_{e, x},
\end{gathered}
$$

where $F_{e, z}$ and $F_{e, x}$ are the external forces applied on the HTS in the $z$-direction and $x$-direction respectively; $z_{r}$ and $x_{r}$ are the vibration-induced displacements of HTS resulted from the unequal electromagnetic force and external force in the respective directions; $m$ is the mass of the mover which includes the mass of HTS and the mass of load. In this work, $m$ is defined as $1 \mathrm{~kg}$ in all sections. The change of position should be embodied into boundary condition, which means (9) should be modified to be,

$\mathbf{H}(\boldsymbol{t})=\boldsymbol{H}_{\text {self }}\left(x(t)+x_{r}(t), y(t), z(t)+z_{r}(t)\right)+$

$\boldsymbol{H}_{\text {ext }}\left(x(t)+x_{r}(t), y(t), z(t)+z_{r}(t)\right)$.

It should be pointed out that $x(t)$ and $z(t)$ describe the relative displacement between HTS and PM in macroscopic view, e.g., field cooling process, whereas $z_{r}$ and $x_{r}$ describe the vibration displacement caused by the non-zero resultant force. This boundary condition also works for electromagnetic-mechanical model which only employs nonlinear relationship in (7) and (8). Note that, (19) and (20) are solved in Global ODEs and DAEs (ge) interface of COMSOL at the same time with electromagnetic-thermal model.

\section{RESUlTS AND DISCUSSION}

In this section, the model is applied to study the dynamic response of a linear HTS maglev bearing under free vibration and typical external excitations, i.e. earthquake, track irregularity and crosswind, as an application example. The methods to restrain the vibration and to improve system stability are also explored.

In sections $A$ and $B$ in this part, the following field cooling process was considered to enable the HTS to be levitated: the HTS moves vertically downward at a speed of $1 \mathrm{~mm} / \mathrm{s}$ from the field cooling position of $30 \mathrm{~mm}$ above the $\mathrm{PM}$, to the working position of $10 \mathrm{~mm}$ above the PM. The relative displacement between HTS and PM can be expressed as,

$$
\begin{gathered}
x(t)=0, \\
z(t)=\left\{\begin{array}{c}
30-t, 0<t \leq 20 \\
10, \quad t>20
\end{array} .\right.
\end{gathered}
$$

The evolution of levitation force during this process is shown in Fig. 3. With the decrease of height, the initial levitation force of $16.5 \mathrm{~N}$ was reached.

Besides, the levitation force and working height calculated by both electromagnetic-thermal-mechanical model and electromagnetic-mechanical model are shown in section A and B in chapter III, for the purpose of exploring the influence of thermal effect on the dynamic responses.

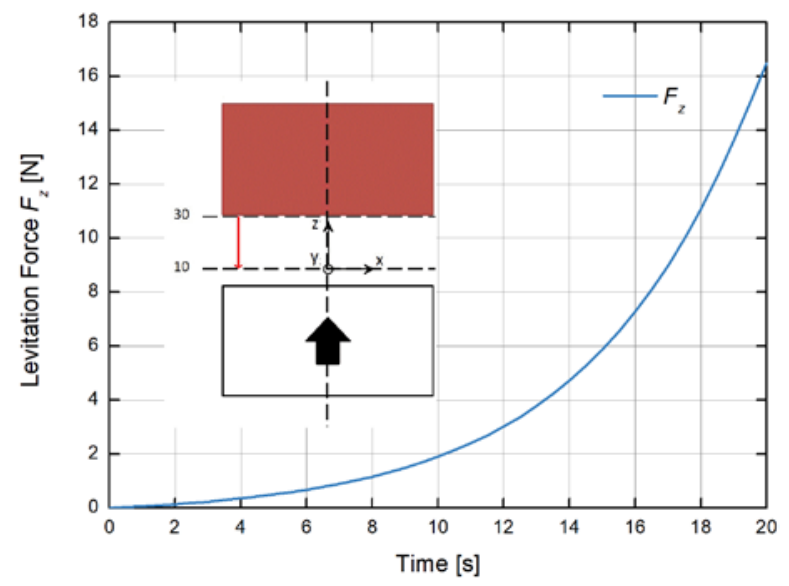

Fig. 3. Levitation force during the field cooling sequence. The inset is the schematic diagram of the field cooling sequence.

\section{A. Free vibration}

During the cooling the bulk is fixed to make it move in $z$ direction at a speed of $1 \mathrm{~mm} / \mathrm{s}$. After the cooling the bulk is released, which means the mechanical constraints on it are taken off. Then it comes into free vibration state. The difference between the initial levitation force and weight, gives it an acceleration and it begins to vibrate.

It can be seen that the initial levitation force is larger than weight, so the vertical displacement is positive. With the increase of position, the magnetic field strength decreases, resulting in the decrease of the levitation force gradually until the maximum position reaches. Then the working height gradually decreases, resulting in the increase of the levitation force gradually until the lowest working height reaches, and then the cyclic oscillation continues to occur.

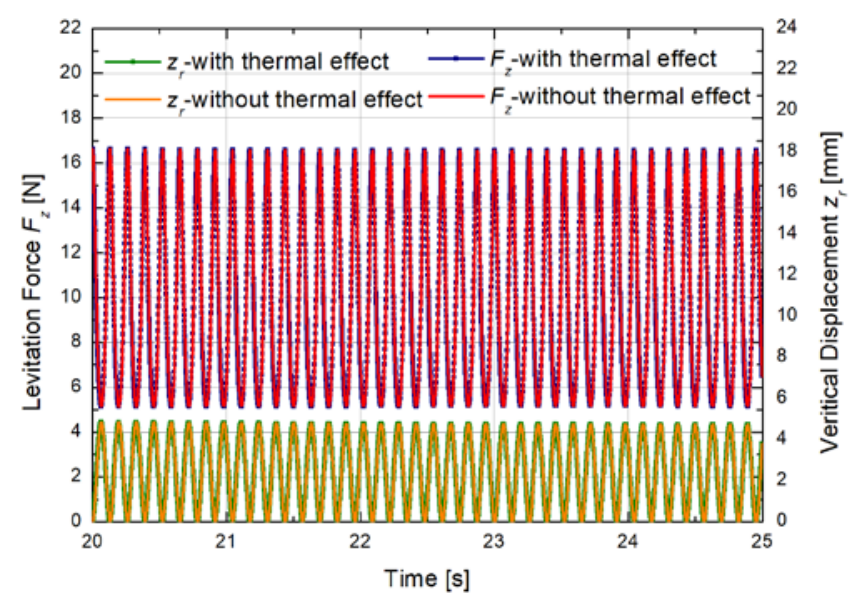

Fig. 4(a). Levitation force and vertical displacement under the free vibration calculated by models with thermal effect (line) and without thermal effect (line and dot). 


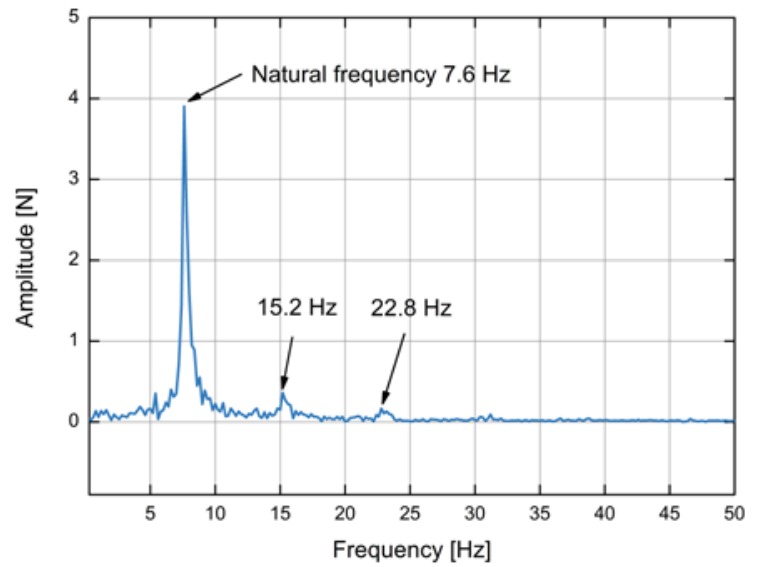

Fig. 4(b). Spectrum analysis of levitation force curve under free vibration state. The frequency at the highest peak point is the natural frequency of system.

The time-dependent curves of levitation force and vertical displacement are shown in Fig. 4(a). It can be found that there is little disparity between respective curves with and without thermal effect. The small disparity can be explained by the limited temperature rise in HTS, which is shown in Fig. 9 together with the temperature rises in other cases. One can see from Fig. 9 that the maximum temperature of HTS almost remained $77 \mathrm{~K}$ during free vibration, leading to little changes after thermal effect is considered.

The natural frequency is an important parameter of the maglev system. One should avoid that the traction motor and other devices work around that frequency. This could induce resonance and lead to serious vibration or even instability of the system. The natural frequency of HTS levitation system can be evaluated by Fourier analysis of levitation force (or displacement) curve in free vibration. As shown in Fig. 4(b), the natural frequency of the studied system is about $7.6 \mathrm{~Hz}$. A slight resonance also occurs at multiples of that frequency of $15.2 \mathrm{~Hz}$ and $22.8 \mathrm{~Hz}$. This phenomenon is consistent with the experimental findings of the vibration response of the linear HTS maglev bearing in [57]. According to the previous work[32], the natural frequency is almost independent of the mass of the suspended body, so it can be regarded as the natural frequency of linear HTS maglev systems composed of same HTS bulk with any mass and the same PM, in the condition of same field cooling height and working height.

\section{B. Dynamic responses of typical excitations}

In this part, analogy methods of three typical external excitations for practical operations in reality, i.e., earthquake, track irregularity and crosswind, are proposed, and the dynamic responses of the aforementioned linear HTS maglev bearing under these excitations will be investigated.

Besides, as we mentioned before, the thermal effect plays little influence when the HTS is in quasistatic state due to limited temperature rise. We accordingly study the influence of thermal effect in dynamic cases. The dynamic responses of the aforementioned linear HTS maglev bearing under these excitations were calculated with and without thermal effect to study the influence of thermal effect.

\section{1) Earthquake}

Although earthquakes occur occasionally, they will have a great impact on the vehicle safety. The influence of earthquake on the levitation performances must be considered in order to clarify the system's anti-seismic capability of the system. Seismic waves are low-frequency compound waves with both longitudinal and transverse waves. The lower the frequency is, the greater the destructiveness is [58].

A negative sine wave with a magnitude of $5 \mathrm{~mm}$ and a frequency of $4 \mathrm{~Hz}$ is selected to imitate a seismic longitudinal wave [58]. The guideway is assumed to be fixed with the ground. The negative sinusoidal vibration of the ground can be therefore regarded as the positive sinusoidal vibration of the HTS taking PM as reference. Thus, the relative displacement of HTS can be expressed as

$$
\begin{gathered}
z(t)=5 \sin (8 \pi t), 25 s>t>20 s, \\
x(t)=0 .
\end{gathered}
$$

The dynamic responses of such linear HTS maglev bearing under seismic longitudinal wave excitation are shown in Fig. 6. Under the influence of seismic longitudinal wave, the vibration of the levitation force and of vertical displacement is obviously stronger than that in free vibration. They both tends gradually to stationary vibration. This implies that the system is able to maintain safe operation under the influence of such seismic longitudinal wave, but the comfort of operation is greatly reduced.

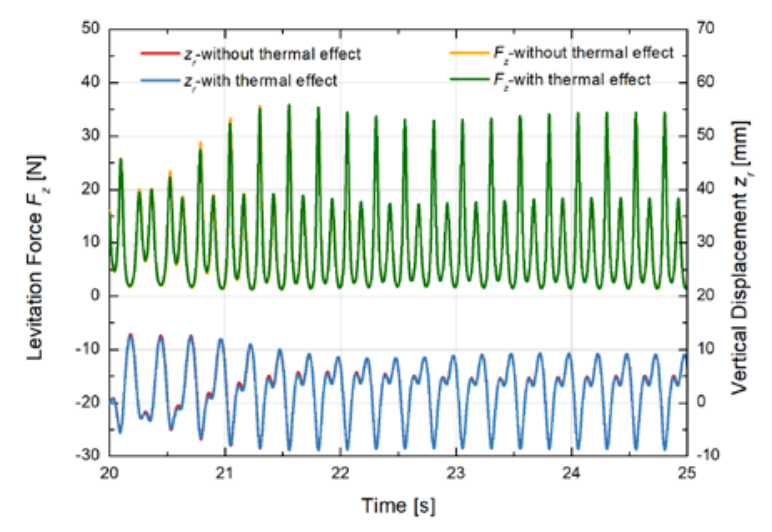

Fig. 5. Levitation force and vertical displacement under seismic longitudinal wave excitation calculated by models with and without thermal effect.

Since the variation of the levitation force is induced by the vertical displacement, the influence of thermal effect is analyzed only from the perspective of vertical displacement. As shown in Fig. 5, at the beginning, the vibration amplitude of vertical displacement is slightly larger with thermal effect. However, as the time evolves, the thermal effect on the vibration curves eventually becomes negligible. The center of the vertical displacement curve gradually decreases from about 5 $\mathrm{mm}$ to nearly zero. This observation indicates that the position of the HTS is also decreased by $5 \mathrm{~mm}$, i.e. the HTS is accompanied by obvious levitation drift under earthquake excitation.

As shown in (13), the temperature of HTS affects the critical current density and then the levitation force and displacement. At the beginning, the temperature in the superconductor rises rapidly which leads to an obvious influence on the levitation performance. In the subsequent vibration, the temperature in the 
HTS bulk gradually decreases due to the heat exchange with the cooling cryogen, and the influence of temperature on the levitation performance gradually decreases. The evolution of the maximum temperature inside the HTS is displayed in Fig. 9.

\section{2) Track irregularity}

The Halbach PM guideways are commonly used to concentrate the magnetic field above the guideway, thus improving the system efficiency [59]. However, due to the limitations of PM manufacturing technology, it is difficult for a single PM to reach a sufficient long length. Therefore, PM with the same magnetization direction must be installed in the guideway's length direction ( $y$-direction), which will inevitably lead to the unequal height or tiny gap at connected parts [60]. This is the main reason for the track irregularity for HTS maglev vehicle.

In this section, to simulate the track irregularity, we assume that the unequal height caused by the installation process occurs every certain distance in the forward $y$-direction, and the height difference is set to $1 \mathrm{~mm}$. During the operation of linear HTS maglev bearing, the working height will change when reaching the exact position above the connected part of PM guideway. Such a change of working height could be regarded as the same relative displacement between the guideway and the car body in the vertical $z$-direction. Therefore, the sine wave can approximately be used to simulate the effect of the track irregularity on the levitation performance. Taking commercially available length of PM $200 \mathrm{~mm}$ as an example, $f=50 \mathrm{~Hz}$ are selected to indicate a speed of $36 \mathrm{~km} / \mathrm{h}$. Thus the relative displacement of HTS can be expressed as

$$
\begin{gathered}
z(t)=\sin (100 \pi t), 25 s>t>20 s, \\
x(t)=0, \mathrm{t}>20,
\end{gathered}
$$

The resulting levitation force and vertical displacement are plotted in Fig. 6 (a) and Fig. 6 (b). The vibrations of levitation force and vertical displacement are apparently stronger than that of free vibration and lighter than that of earthquake.

One can see from Fig. 6(b) that, the vibration tends to steadystate vibration after about 3 seconds without thermal effect, but only about 1 second with thermal effect. Concerning the amplitude, the amplitude of the vertical displacement curve with thermal effect is smaller than that without thermal effect. This phenomenon is similar with earthquake case, but much more obvious. With regard to phase, there is almost no phase difference between the two curves at the beginning, but, the phase difference increases gradually as the time develops. About 4 seconds after the starting of vibration, the vertical displacement curve with thermal effect is almost half a period ahead of that without thermal effect. Besides, the levitation drift is smaller with thermal effect, as we can see in Fig. 6.

All the above difference can be interpreted from the perspective of energy dissipation: in the model without thermal effects, the energy brought by external excitation destroys the original steady state of the system, and the system can only consume this energy through vibration; while an extra part of energy can be dissipated in the form of heat in the model with thermal effect which will lead to a smaller amplitude, a shorter period during vibration and a smaller levitation drift.

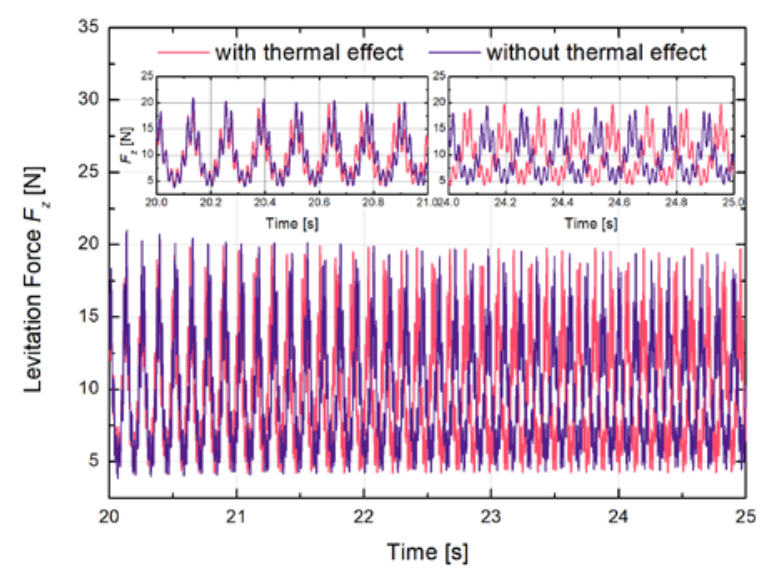

Fig. 6(a). Levitation force under track irregularity excitation calculated by models with and without thermal effect. The inset shows the force at the beginning of the excitation and 4 seconds after.

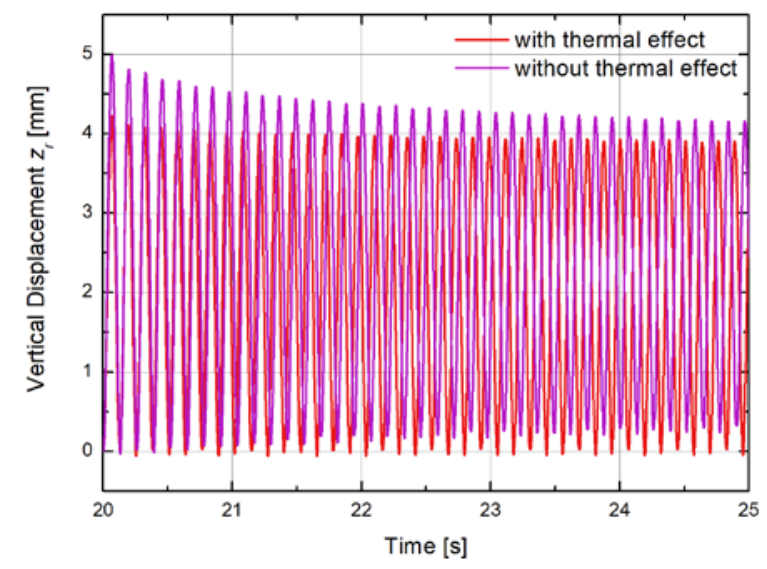

Fig. 6(b). Vertical displacement under track irregularity excitation calculated by models with and without thermal effect.

\section{3) Crosswind}

Crosswind is another crucial factor affecting the operation safety. The linear HTS maglev bearings have the ability to resist crosswind due to their self-stable ability. However, the specific dynamic response of the system to crosswind is still worthy of attention in order to quantify and determine the threshold of lateral stability of the system. This is of great significance for further application of linear HTS maglev bearing in the transportation system.

In this regard, the method to calculate the vibrational response under crosswind excitation is presented in this paper. The crosswind acts on the lateral side of carbody, i.e., $x$-direction. According to the dynamics theory, the force acting on the HTS body is as follows:

$$
F_{\text {ex }}=0.5 C_{d} A \rho v^{2},
$$

where $C_{d}$ is the air drag coefficient which is only dependent on the shape of the object. For example, $C_{d}=1$ models a vertical plane and $C_{d}=0.5$ is used for a sphere. $A$ is the characteristic area (windward area) of the HTS body. $\rho$ is the density of air, we used $\rho=1.2258 \mathrm{~N} \cdot \mathrm{s}^{2} \cdot \mathrm{m}^{-4}$ for dry air. $v$ is the speed of wind. Taking gale wind $(v=20.7 \mathrm{~m} / \mathrm{s})$ as an example, the dynamic response of the HTS maglev bearing in Fig. 1 is calculated. In this 
case, the characteristic area equals $4.5^{*} 10^{-4} \mathrm{~m}^{2}$ and $C_{d}=0.5$ can be used approximately, finally $F_{e x}=0.06 \mathrm{~N}$ is obtained according to (26).

Differing from previous cases, the crosswind will result in the vibrations both in vertical and lateral directions together, thus the vibrations in both directions must be considered at the same time. The results were sketched in Figs. 7(a) and 7(b) respectively. When the HTS is positioned directly above the PM, the guidance force is zero. Under the influence of crosswind, the lateral displacement is generated and so is the guidance force. The guidance force, as given in (12), increases with the lateral displacement, but when the HTS bulk goes too far, the guidance force will decrease as the magnetic field strength abates. As shown in Fig. 7(b), the curves of levitation force and vertical displacement are almost same as that in free levitation, which implies the excellent self-stability of HTS maglev system. In addition, the levitation force and vertical displacement curves with thermal effect are also almost identical with that without thermal effect respectively, indicating that temperature rise in this case is quite small which is demonstrated in Fig. 9.

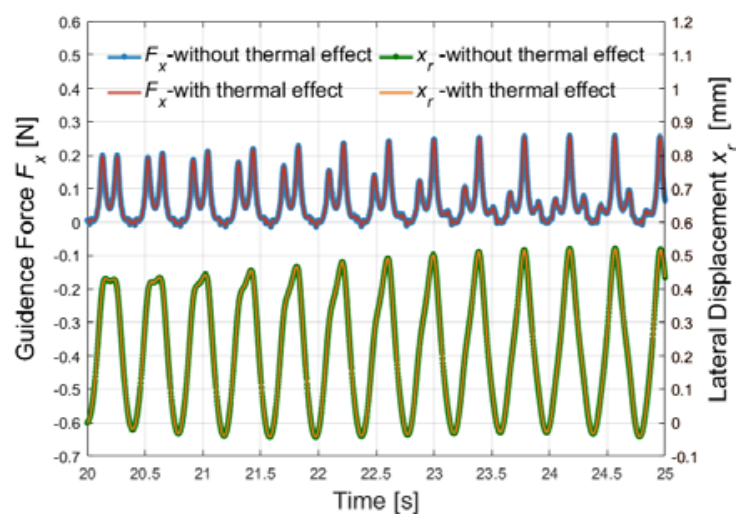

Fig. 7(a). Guidance force and lateral displacement under crosswind excitation calculated by models with thermal effect (line) and without thermal effect (line and dot).

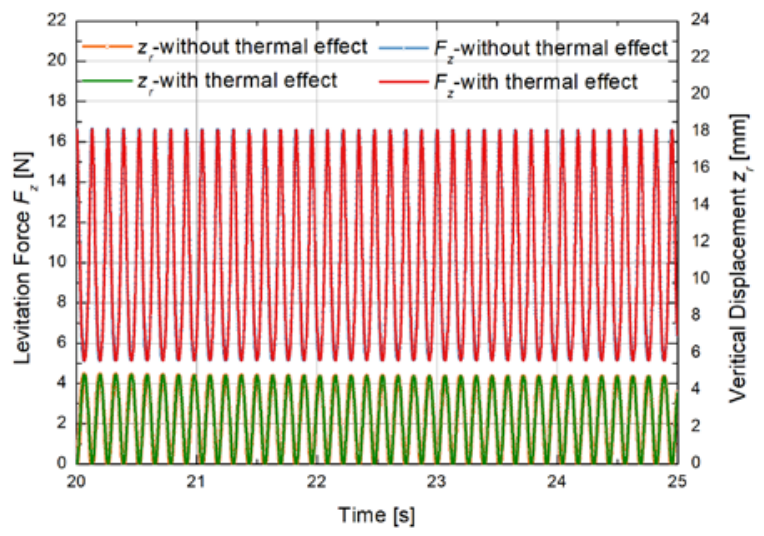

Fig. 7(b). Levitation force and vertical displacement under crosswind excitation calculated by models with thermal effect (line) and without thermal effect (line and dot).

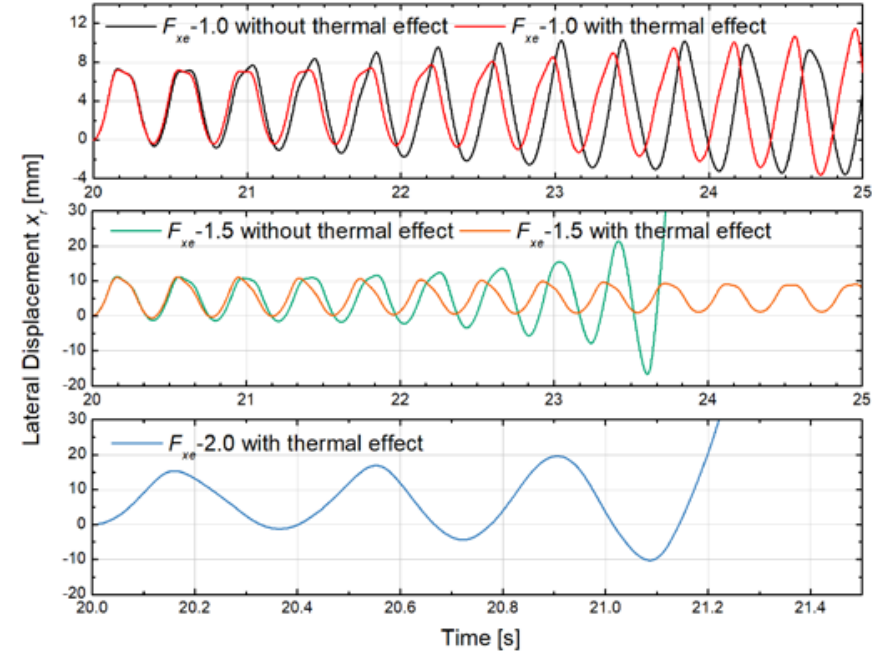

Fig. 8 Lateral displacement curves under different lateral forces.

Although being self-stable, the self-stability ability of HTS is limited. Therefore, it is necessary to find out the critical conditions of instability to ensure the safe operation. Different lateral forces of $1.0 \mathrm{~N}, 1.5 \mathrm{~N}$ and $2.0 \mathrm{~N}$ are applied to find the threshold of lateral recoverability, as Fig. 8 shown. The thresholds of lateral force calculated from model with and without thermal effect is $2.0 \mathrm{~N}$ and $1.5 \mathrm{~N}$ respectively. This result indicates that the lateral displacement with thermal effect is smaller than that without thermal effect, leading to the difference between the thresholds of lateral force that the studied HTS maglev system can withstand from the two models. The model with thermal effect no longer imitates a conservative system.

4) Temperature rise

The performance of a linear HTS maglev bearing is closely associated to thermal effect and could be illustrated directly by HTS temperature. Owing to the non-uniform thermal distribution inside the HTS, the time evolution of the maximum temperature inside the HTS and the thermal distribution when the highest maximum temperature is reached, are selected to analyze the thermal effect.

The maximum temperature inside the HTS for all previous cases are sketched in Fig. 9. The temperature rise is clearly limited, as the highest temperature is only $77.2 \mathrm{~K}$. Nevertheless, a large difference can be observed between the different cases. From the discussions of previous sections, one can conclude that the temperature in the HTS is directly related to the external excitation. The stronger the external excitation, the more intense the internal temperature rise. For periodic excitations such as earthquake and track irregularity, the HTS temperature is also related the frequency as discussed before.

As they have the highest maximum temperature, the thermal distributions for the earthquake and $2.0 \mathrm{~N}$ crosswind excitations are shown in Fig. 10. The highest temperature zone is located close to the bottom edge of the HTS bulk where the magnetic field gradient is the strongest. Therefore, one should pay attention to the bottom edge of HTS during the design if quench detection is needed. 


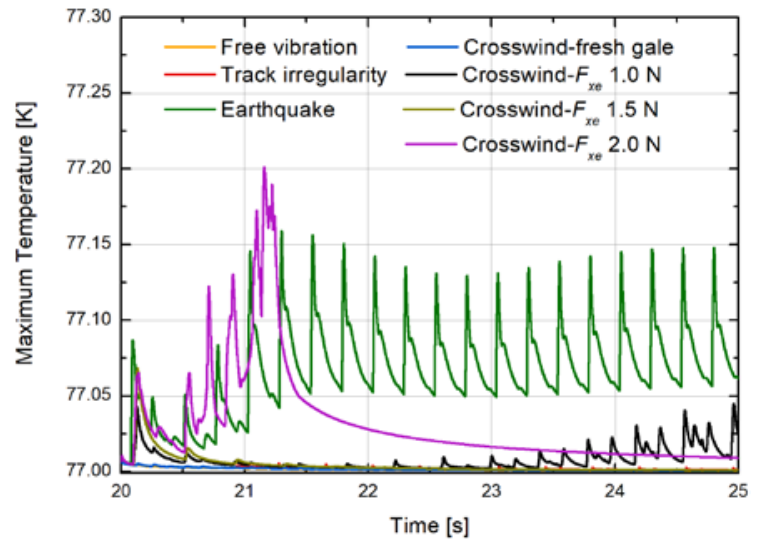

Fig. 9. The evolution of maximum temperature inside the HTS bulk under diverse excitations.

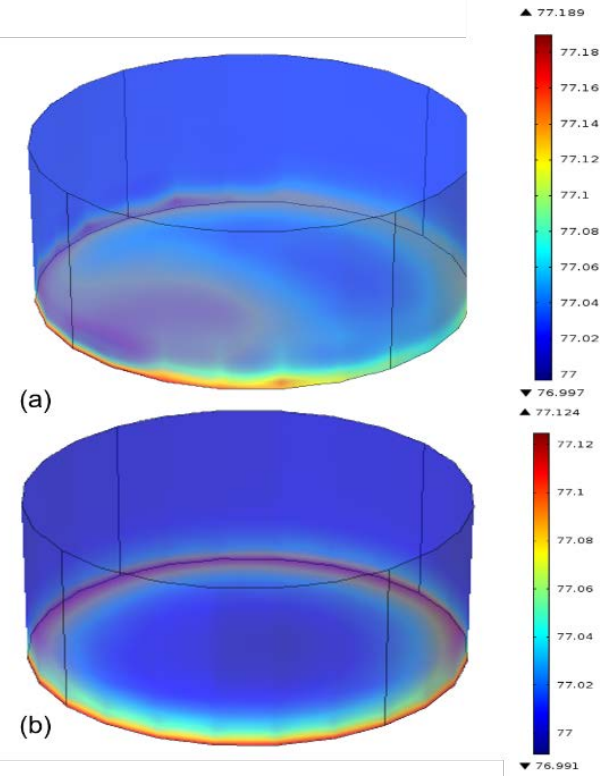

Fig. 10. Thermal distribution inside the HTS bulk when the maximum temperature is achieved. (a) lateral force $2.0 \mathrm{~N}$ (2) earthquake excitation.

\section{Methods to improve system stability}

From the above discussion one can conclude that the coupling of thermal effect will lead to the difference of dynamic response of the system under external excitations. The model with thermal effect is relatively closer to the reality and the result calculated with thermal effect make more sense than that without thermal effect. Thus it's better to explore the methods to improve the system stability using the model with thermal effect.

In this part, the influence of field cooling height (FCH), preload and ambient temperature in system stability were discussed. Considering the vertical stability and lateral stability, the track irregularity and crosswind with $1.5 \mathrm{~N}$ lateral force are selected therefore as applied excitations respectively for all the cases in this section. Also, the working heights for all the cases in this section keep as $10 \mathrm{~mm}$.

\section{1) Influence of $\mathrm{FCH}$}

The FCH determines the initial magnetic flux trapped by the HTS. This impacts the load-carrying capacity as well as the dynamic characteristics. Depending on the actual application, the selection range for the working height is relatively small. It is more instructive consequently to study the influence of different FCHs under the given working height for engineering application.

Reference [37] investigated the influence of FCH only for the case of vertical free vibration by simplifying free vibration curves to common dynamic model equation. There is little literature concerning the influence of FCH that takes real non-linear superconducting electromagnetic properties into consideration. Also, the influence of FCH under complex external excitations and the influence of FCH on the lateral stability remain open, to the best of our knowledge.

With the same working height being $10 \mathrm{~mm}$, three typical FCHs (30 mm, $40 \mathrm{~mm}$, and $70 \mathrm{~mm}$ ) plus zero field cooling $(\mathrm{FCH}=100 \mathrm{~mm}$ ) were taken as examples. The results of cooling sequences with different FCHs are shown in Fig. 11.

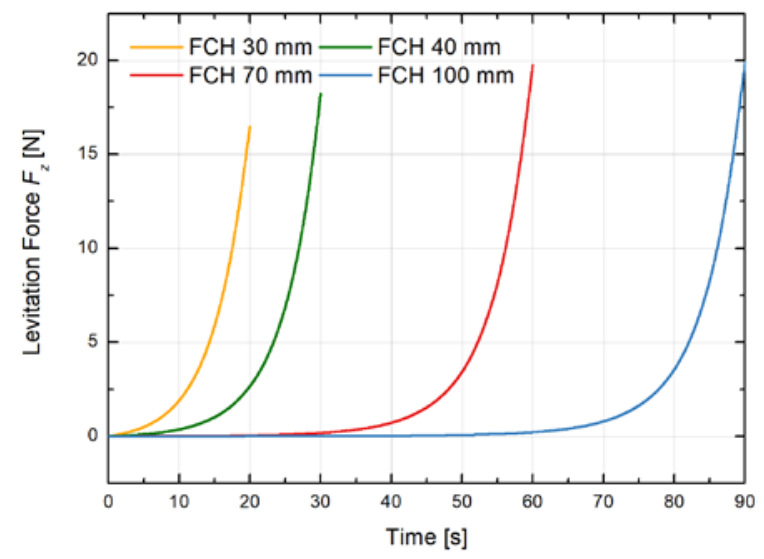

Fig. 11. Levitation forces during sequences with FCH of 30, 40, 70 and 100 $\mathrm{mm}$.

\section{a) Vertical stability}

As shown in Fig. 11, the larger the FCH, the larger the levitation force at the end of the cooling sequence. It is worthy to point out that the increase of load-carrying capacity with FCH is not linear. With same interval of $30 \mathrm{~mm}$, the increase of levitation force from FCH 40 to $70 \mathrm{~mm}$ is $1.5 \mathrm{~N}$, which is much larger than the increase from FCH 70 to $100 \mathrm{~mm}$, i.e. $0.06 \mathrm{~N}$. Therefore, blindly choosing the highest FCH is not the most "economical" way to improve the load-carrying capacity.

The vertical displacements and their envelope lines under the track irregularity excitation with different FCHs were depicted in Fig. 12. Under the same external excitation, the smaller the amplitude of vertical displacement, the better the stability of the system. Noting that the amplitude of the displacement for the FCH $100 \mathrm{~mm}$ is slightly less than that with FCH $70 \mathrm{~mm}$, we can conclude therefore that the vertical stability of the system decreases firstly and then increases with the increase of FCH. This conclusion is similar to that of [37], in which the study was performed under free vibration state. In [37] the vertical stiffness 
increase with the decrease of the FCH on the whole in free vibration case, but exception could be found at FCH $40 \mathrm{~mm}$. FCH 40 is the turning point of the varying trend of stiffness in [37], just like FCH $70 \mathrm{~mm}$ in this work.

Accordingly, conclusion could also be drawn that regardless of existence of external excitations, the vertical stability of the linear HTS maglev bearing decreases firstly and then increases with the increase of FCH. The turning point varies from different systems. The reason for this nonlinear varying trend is still in vague and deserves much attempt in future research.

Besides, one fact that cannot be ignored is that the above results are calculated with same loading weight, however, loading weight is also positively related to the stability. As a result of this, for this contradiction between load-carrying capacity and vertical stability, the potential solution is to increase the loading weight properly after the load-carrying capacity is enhanced through increasing the FCH to enhance the vertical stability of the system.

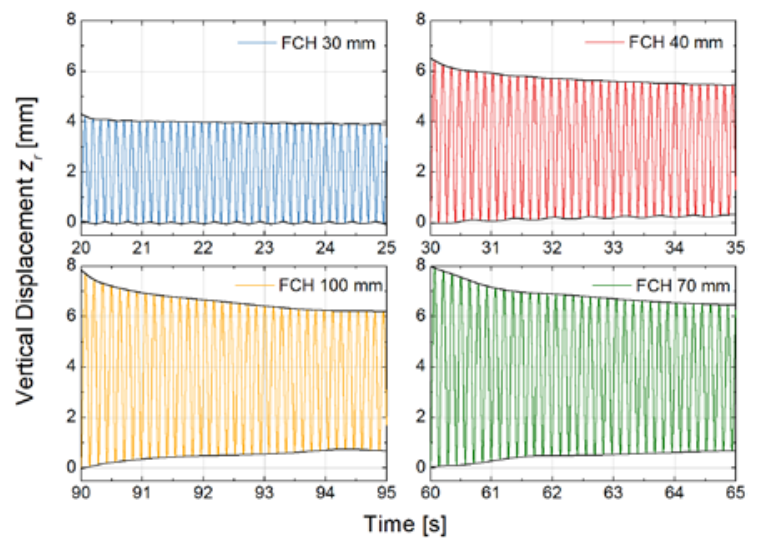

Fig. 12 Vertical displacements under the track irregularity excitation with FCH of 30, 40, 70, and $100 \mathrm{~mm}$.

\section{b) Lateral stability}

The lateral displacements and guidance forces under crosswind with $1.5 \mathrm{~N}$ lateral force excitation are depicted in Figs. 13(a) and 13(b) respectively. The influences of the FCH on both the amplitude and frequency can be found in Fig. 13. With the increase of FCH, the amplitude of the lateral displacement increases firstly and then decreases, while the frequency increases except when $\mathrm{FCH}=70 \mathrm{~mm}$. The lateral stability decreases with the increase of FCH firstly, thus when FCH reaches $70 \mathrm{~mm}$ the system cannot bear such lateral excitation and the guidance force becomes zero after the HTS bulk is "blown" away. It can be seen that the influence of FCH on lateral stability is stronger than that on vertical stability, recalling extra attention on the lateral stability when selecting FCH.

To conclude, both vertical and lateral stability decrease firstly and then increase with the increase of FCH. Its influence on the lateral stability, however, is stronger than the influence on vertical stability. Although this dilemma can be solved by increasing the loading weight to some extent, the tradeoff between stability and load-carrying capacity still need to be made cautiously.

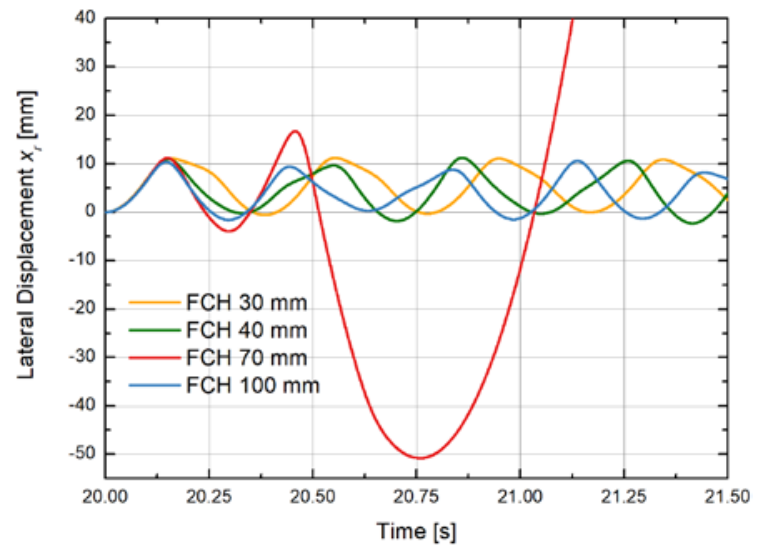

Fig. 13(a) Lateral displacements under crosswind with $1.5 \mathrm{~N}$ excitation. The guidance force becomes zero after the HTS bulk is "blown" away with FCH 70 $\mathrm{mm}$. Thus the curve of lateral displacement at FCH $70 \mathrm{~mm}$ is not complete.

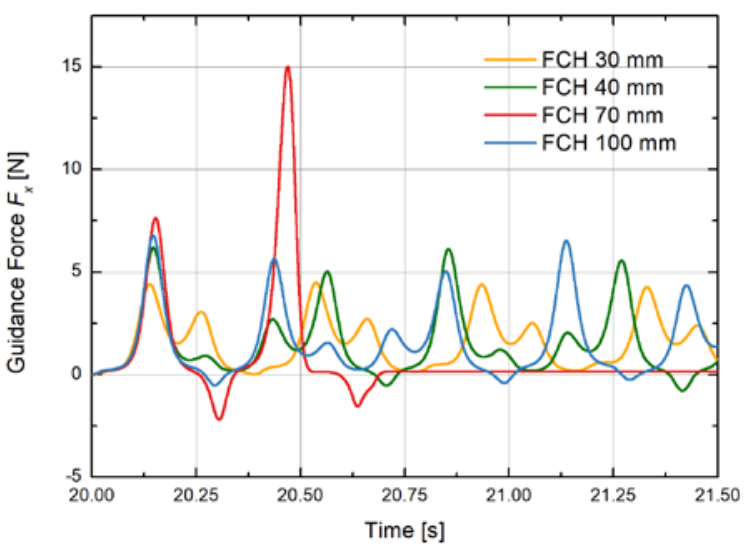

Fig. 13(b) Lateral forces under crosswind with $1.5 \mathrm{~N}$ excitation.

2) Influence of pre-load

Pre-load method was put forward in [61] to reduce levitation force decay and was verified further in[56] and [62]. There are little studies related to the influence of pre-load on the vibration performance of the linear HTS maglev bearing to our knowledge. The responses to aforementioned excitations calculated without pre-load are reported too as the reference.

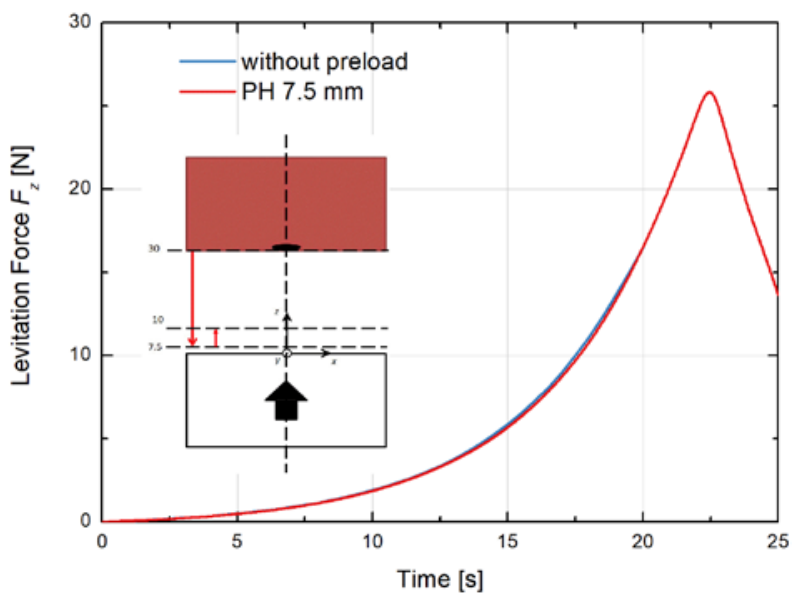

Fig. 14(a) Levitation forces during pre-load. The HTS bulk firstly descends vertically from $30 \mathrm{~mm}$ to pre-load height $(\mathrm{PH}) 7.5 \mathrm{~mm}$ above the center of $\mathrm{PM}$, and then returns upward to its working height of $10 \mathrm{~mm}$. 


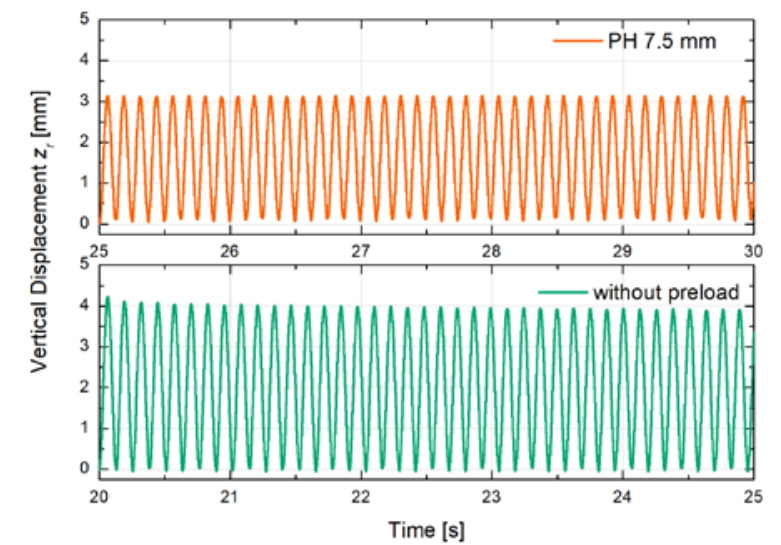

Fig. 14(b) Vertical displacements under track irregularity excitation calculated with and without pre-load. In order to express the tendency more intuitively, same $y$-axis scale was used in 2 subplots.

\section{a) Vertical stability}

The levitation forces during pre-load and the vertical displacements under the track irregularity excitation calculated with and without pre-load are sketched in Figs. 14(a) and 14(b) respectively. It can be found that $17.3 \%$ of levitation force is lost after pre-load. Under the same track irregularity excitation, the amplitude of vertical displacement decreases by $24.9 \%$ in terms of the last complete wave before calculation finished. This result could be interpreted as that the vertical stability could be greatly enhanced by pre-load while the load-carrying capacity is slightly decreased. Note that the pre-load could also reduce the levitation force decay. Therefore, the pre-load process is still worthwhile for its dual merits of reducing levitation force decay and enhancing vertical stability in terms of cost performance.

\section{b) Lateral stability}

The lateral displacements and guidance forces under crosswind with $1.5 \mathrm{~N}$ lateral force excitation are depicted in Fig. 15(a) and Fig. 15(b) respectively. It can be seen that the system can maintain in operation before preload, however, it cannot bear same excitation after pre-load as shown in Fig.15. This phenomenon indicates that the lateral stability of the studied system weakens more or less after the pre-load unfortunately.

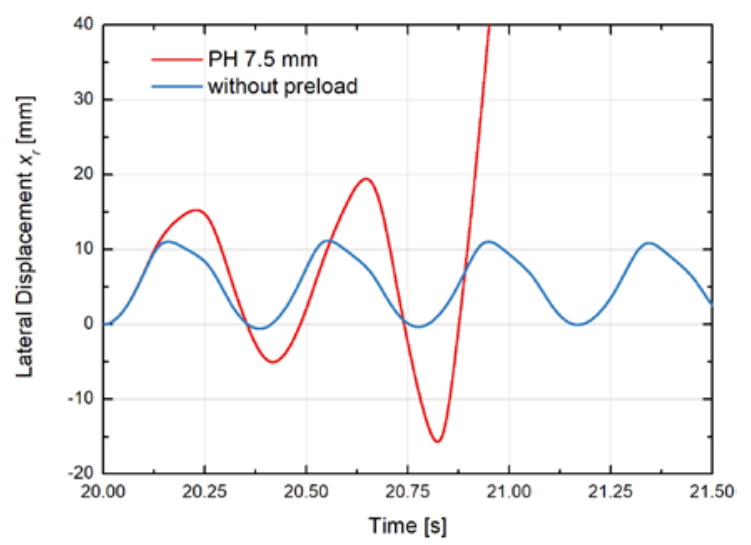

Fig. 15(a) Lateral displacements under crosswind with $1.5 \mathrm{~N}$ excitation. The guidance force becomes zero after pre-load, thus the curve of lateral displacement with pre-load is not complete.

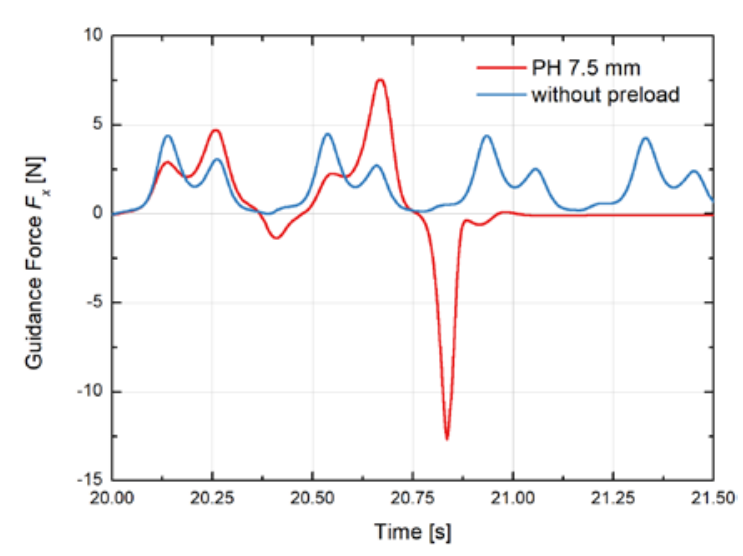

Fig. 15(b) Lateral forces under crosswind with $1.5 \mathrm{~N}$ excitation.

\section{3) Ambient temperature}

It is known that the lower the ambient temperature, the larger levitation force the system could obtain. This is to say the load capacity of the linear HTS maglev bearing could be strengthened with lower ambient temperature. But what is the influence of ambient temperature on the dynamic performance of linear HTS maglev bearing still stays unclear. In this part the dynamic responses under track irregularity and crosswind excitations at different ambient temperatures were consequently calculated.

The parameters of the thermal model in this work are chosen based on the liquid nitrogen cooling. We have to claim that there is a liquid-solid phase transition for liquid nitrogen when temperature drops to about $63.5 \mathrm{~K}$. It will be solidified to solid nitrogen if being cooled in further step [63]. The thermal properties of solid nitrogen are greatly different from that of liquid nitrogen, so is the cooling from solid nitrogen to the HTS bulk. Also, the existence of solid nitrogen will also affect the dynamic response of the system during vibration. As a result, ambient temperatures above $63.5 \mathrm{~K}$, i.e. $77 \mathrm{~K}, 70 \mathrm{~K}$ and $65 \mathrm{~K}$ are selected in this work.

With FCH $30 \mathrm{~mm}$ and working height $10 \mathrm{~mm}$, the levitation forces during field cooling with different ambient temperatures are shown in Fig. 16. The final levitation force for $65 \mathrm{~K}, 70 \mathrm{~K}$ and $77 \mathrm{~K}$ is $17.32 \mathrm{~N}, 17.22 \mathrm{~N}$ and $16.50 \mathrm{~N}$ respectively.

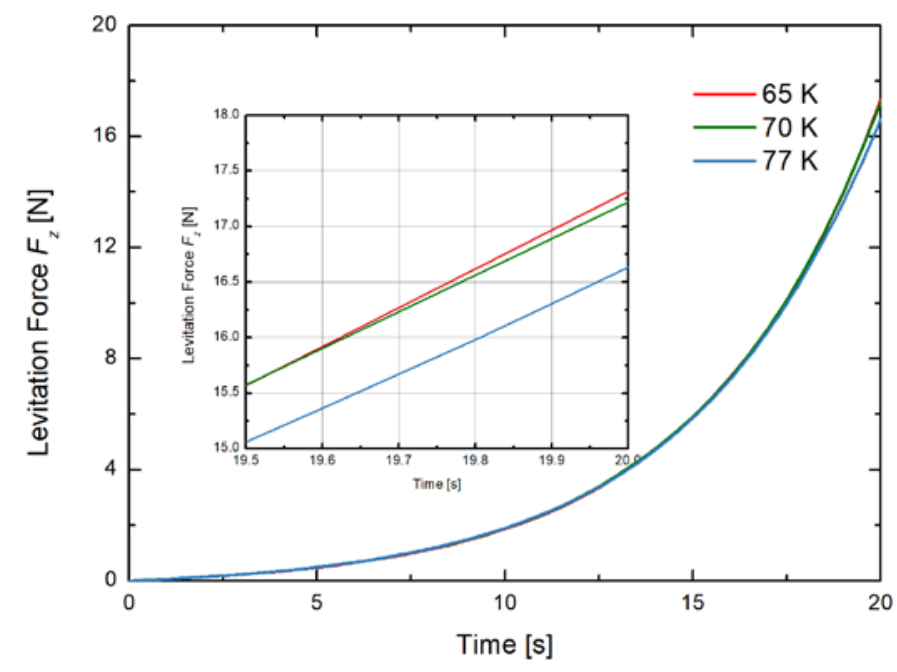

Fig. 16 The levitation forces during field cooling with different ambient temperatures. 


\section{a) Vertical stability}

The vertical displacements under the track irregularity excitation with different ambient temperatures are sketched in Fig. 17 . With the decrease of the temperature, the amplitude of vertical displacement gradually increases, which keep consistent with the trend of obtained levitation force after field cooling.

Compared with the obtained levitation force after field cooling at $77 \mathrm{~K}$, the levitation force increases by $4.36 \%$ and $4.97 \%$ respectively for $70 \mathrm{~K}$ and $65 \mathrm{~K}$. In terms of the amplitude of the last wave of vertical displacement curve before the calculation ends, it increases by $33.60 \%$ and $40.80 \%$ respectively for $70 \mathrm{~K}$ and $65 \mathrm{~K}$, compared with that at $77 \mathrm{~K}$. One can conclude therefore that, although lower ambient temperature could increase the load capacity of system, however, it decreases the vertical stability of the system.

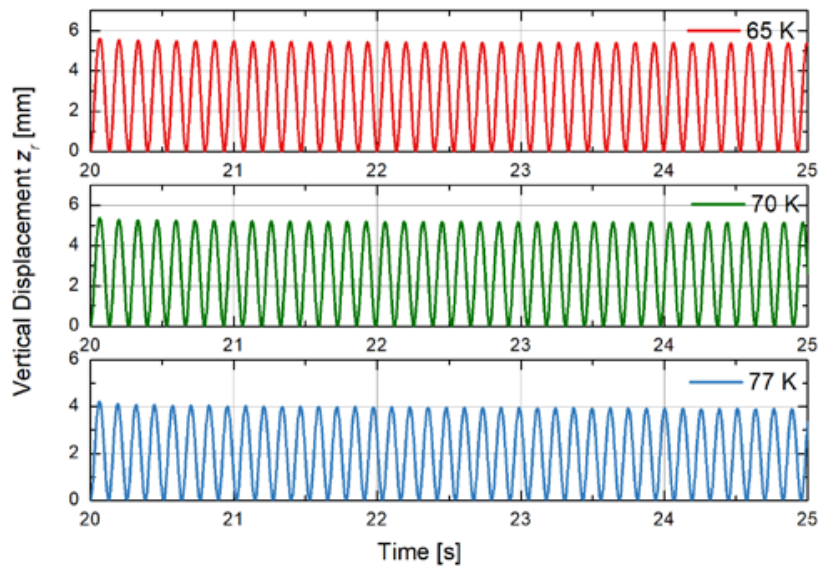

Fig. 17 Vertical displacements under the track irregularity excitation with different ambient temperatures. In order to express the tendency more intuitively, same y-axis scale was used.

\section{b) Lateral stability}

The lateral displacements under crosswind with $1.5 \mathrm{~N}$ lateral force excitation at different ambient temperatures are depicted in Fig. 18.

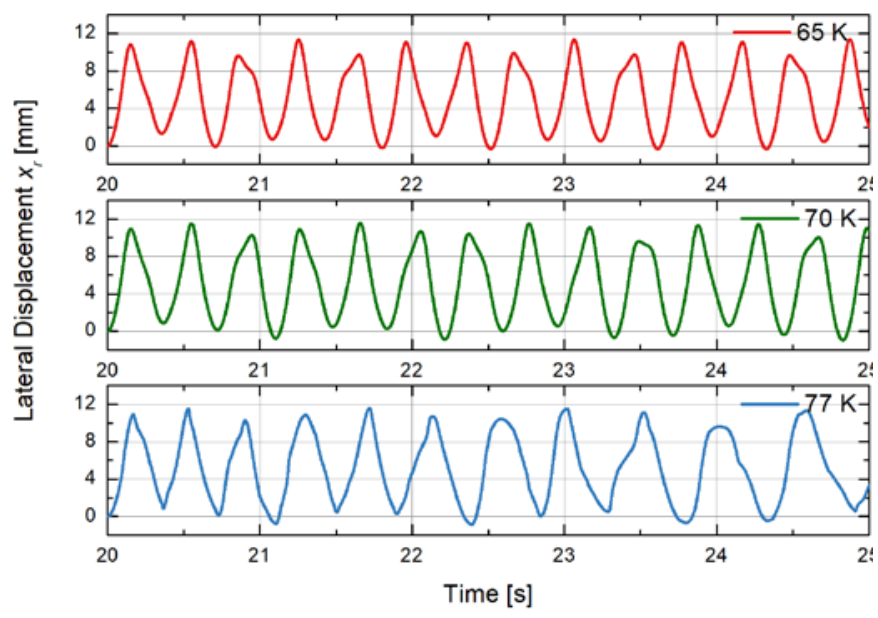

Fig. 18 Lateral displacements under crosswind with $1.5 \mathrm{~N}$ lateral force excitation at different ambient temperatures. In order to express the tendency more intuitively, same y-axis scale was used.
In can be seen from Fig. 18 that the amplitude of lateral displacements at $77 \mathrm{~K}, 70 \mathrm{~K}$ and $65 \mathrm{~K}$ are similar. This does not mean that the ambient temperature has little influence on lateral stability. There are 11, 13 and 14 peaks in lateral displacement curve at $77 \mathrm{~K}, 70 \mathrm{~K}$ and $65 \mathrm{~K}$ respectively, which means the frequency of the lateral vibration increases. Accordingly, increasing ambient temperature may weaken the lateral stability. Besides this work, similar conclusion was drawn in [45], in which the influence of ambient temperature on the lateral stability of a rotational HTS maglev bearing was studied.

\section{CONCLUSION}

In this paper, a validated three-dimensional strong-coupled electromagnetic-thermal model for HTS bulk was established with the significance of HTS thermal effect realized. It includes both the non-linear electromagnetic characteristics and the thermal characteristics of the HTS material. This model is of great potential to be used in various studies, for example the thermal analysis of HTS bulk in pulse magnetization process, HTS bulk-based electrical machines with proper modifications. Considering the systematicness and completeness of the paper, the emphasis of this paper is lied in the application of the established electromagnetic-thermal model in studying the dynamic characteristics of a linear HTS maglev bearing. To predict the dynamics of the studied system, it is coupled with motion equations further.

The dynamic responses of a linear HTS maglev bearing under typical excitations for its application, i.e. earthquake, track irregularity and crosswind, were calculated systematically with and without thermal effect. Also, the influence of FCH, preload and ambient temperature on system stability were discussed with the help of this model to find the methods to improve the system stability for future real-scale applications. The significant conclusions obtained in this work are listed as follows:

(a) The influence of thermal effect is greatly dependent on the external excitation. The stronger the external excitation, the more obvious the influence. Generally speaking, due to the extra part of energy that can be dissipated in the form of heat, with thermal effect taken into consideration, the amplitude of vibrational displacement is smaller; the period of vibration curve is shorter; and the levitation drift is also smaller. Therefore, in the prediction of the safety threshold in the future application of linear HTS maglev bearing, the vibrational displacement can be calculated with model without thermal effect considering the computing-time consumption.

(b) Concerning the temperature rise, the stronger the external excitation, the more intense the internal temperature rise is. Besides, through looking at the temperature distribution inside HTS bulk, which are inaccessible by means of 2-D models, it can be found the higher temperature zone is located close to the bottom edge of HTS bulk. Therefore, the area close to the bottom edge of HTS should be paid more attention during the design phase if quench detection is needed. 
(c) Concerning the $\mathrm{FCH}$, although a better load-carrying capacity could be obtained through larger FCH, both vertical and lateral stability decrease firstly and then increase with the increase of FCH. And its influence on the lateral stability, is stronger than the influence on vertical stability. Although this dilemma can be solved by increasing the loading weight to some extent, the tradeoff between stability and load-carrying capacity still need to be made cautiously.

(d) Concerning the pre-load, the vertical stability could be greatly enhanced by pre-load with load-carrying capacity slightly decreased; however, the lateral stability is weakened after pre-load unfortunately. A comprehensive measurement therefore could be taken as a compromise in future applications: one can apply pre-load process to enhance vertical stability, and increase FCH at the same time in order to increase loading weight to ensure lateral stability.

(e) Concerning the ambient temperature, although a better load-carrying capacity could be obtained through decreasing ambient temperature, it may weaken the vertical stability and lateral stability at the same time. The tradeoff between load-carrying capacity and stability need to be made cautiously too.

To conclude, although being based on the ideal simplification of practical linear HTS maglev bearing, this paper could still qualitatively provide a guideline for the design of linear HTS maglev systems for transportation, electromagnetic launching and other related applications. Promising methods to enhance the dynamic stability of the system ware also put forward. More importantly, a comprehensive electromagnetic-thermal-mechanical model for HTS bulk was built in this work. It can serve as the theoretical foundation, through which more precise simulation will be available in future study on various HTS bulkrelated engineering applications.

\section{REFERENCES}

[1] J. Wang, S. Wang, Y. Zeng, et al, “The first man-loading high temperature superconducting Maglev test vehicle in the world,” Phy. C, vol. 378, no. 2, Oct. 2002, 809-814.

[2] Z. Deng, W. Zhang, J. Zheng, et al, "A High-Temperature Superconducting Maglev Ring Test Line Developed in Chengdu, China,” IEEE Trans. Appl. Supercond., vol. 26, no. 6, Sept. 2016, Art. no. 3602408

[3] L Schultz, O. D. Haas, P. Verges, et al, "Superconductively levitated transport system -the SupraTrans project," IEEE Trans. Appl. Supercond., vol. 15, no.2, June 2005, 2301-2305.

[4] C. Beyer, O. D. Haas, P. Verges, et al, "Guideway and turnout switch for the SupraTrans project,” J. Phys.: Conf. Ser., vol.43, 2006, 991-994.

[5] L. Kuehn , O. D. Haas, D. Berger, et al, "Supratrans II - test drive facility for a superconductor-based maglev train," Elektrische Bahnen, vol.110, no.8, Dec. 2012, 461-469(in Germany).

[6] G. G. Sotelo, D. H. J. N. Dias, R. A. H. D. Oliveira, et al, "MagLev Cobra: Test Facilities and Operational Experiments,” J. Phys.: Conf. Ser., vol.507, no.3, 2014, Art. no. 032017.

[7] L. S. Mattos, E. Rodriguez, F. Costa, et al, "MagLev-Cobra Operational Test,” IEEE Trans. Appl. Supercond., vol.26, no.3, Apr. 2016, Art. no. 3600704

[8] K. Kovalev, "Magnetically Levitated High-Speed Carriages On Basis of Bulk HTS Elements," Proceeding of the 8th international symposium on magnetic suspension technology. Germany: Dresden, 2005:51.

[9] J. Jin, L. Zheng, W. Xu, et al, "Thrust characteristics of a double-sided high temperature superconducting linear synchronous motor with a high temperature superconducting magnetic suspension system,” J. Appl. Phy., vol. 109, no, 7, Apr. 2011, Art. no. 073916.

[10] F. N. Werfel, U. Floegel-Delor, R. Rothfeld, et al, "Superconductor bearings, flywheels and transportation,” Supercond. Sci. Tech., vol. 25, no.1, 2012, Art. no. 014007.

[11] J. H. Durrell, A. R. Dennis, J. Jaroszynski, et al, "A trapped field of 17.6 T in melt-processed, bulk Gd-Ba-Cu-O reinforced with shrink-fit steel," Supercond. Sci. Tech., vol.27, no.8, July 2014, Art. no. 082001.

[12] M. Tomita, M. Murakami, "High-temperature superconductor bulk magnets that can trap magnetic fields of over 17 tesla at 29K," Nature, vol. 421, no. 6299, 2003, 517-520.

[13] J. H. Durrell, M. D. Ainslie, D. Zhou, et al, "Bulk superconductors: a roadmap to applications," Supercond. Sci. Tech., vol. 31, no.10, Sept. 2018, Art. no. 103501.

[14] F. Sirois, F. Grilli, "Potential and limits of numerical modelling for supporting the development of HTS devices," Supercond. Sci. Tech., vol. 28, no.4, Mar. 2014, Art. no. 043002.

[15] Z. Hong, A. M. Campbell, T. A. Coombs, "Numerical solution of critical state in superconductivity by finite element software," Supercond. Sci. Tech., vol. 19, no. 12, Oct. 2006, 1246-1252.

[16] M. Zhang, T. A. Coombs, "3D modeling of high-Tc superconductors by finite element softwar,” Supercond. Sci. Tech., vol. 25, no. 1, Dec. 2011, Art. no. 015009.

[17] G. T. Ma, H. Liu, X. T. Li, et al, "Numerical simulations of the mutual effect among the superconducting constituents in a levitation system with translational symmetry,” J. Appl. Phy., vol. 115, no. 8, 2014, Art. no. 083908.

[18] L. Alloui, F. Bouillault, L. Bernard, et al, "3D modeling of forces between magnet and HTS in a levitation system using new approach of the control volume method based on an unstructured grid," Phy. C: Supercond. App., vol.475, 2012, 32-37.

[19] J. PenA-Roche, A. Badía-Majós, "Modelling toolkit for simulation of maglev devices,” Supercond. Sci. Tech., vol. 30, no. 1, 2017, Art. no. 014012.

[20] A. Badia-Majos, A. Aliaga, J. Letosa, et al, "Trade-off modeling of superconducting levitation machines: theory and experiment," IEEE Trans. Appl. Supercond., vol.25, no. 4, Aug. 2015, Art. no. 3601810.

[21] H. Mochizuki, H. Fujishiro, T. Naito, et al, "Trapped Field Characteristics and Fracture Behavior of REBaCuO Bulk Ring During Pulsed Field Magnetization," IEEE Trans. Appl. Supercond., June 2016, vol. 26, no. 4., Art. no. 6800205.

[22] M. D. Ainslie, H. Fujishiro, "Modelling of bulk superconductor magnetization,” Supercond. Sci. Tech., vol. 28. No. 5, March, 2015, Art. no. 053002.

[23] K. Haran, S. Kalsi, T. Arndt, et al, "High power density superconducting rotating machines - Development status and technology roadmap," Supercond. Sci. Tech., vol. 30, no. 12, 2017, Art. no. 123002.

[24] F. C. Moon, "Chaotic vibrations of a magnet near a superconductor," Phy. Lett. A, vol. 132, no. 5, Oct. 1988, 249-252.

[25] T. Hikihara, F. C, Moon, "Chaotic levitated motion of a magnet supported by superconductor,” Phy. Lett. A, vol. 191, no. 3, Aug. 1994, 279-284.

[26] B. R. Weinberger, L. Lynds, J. R. Hull, "Magnetic bearings using hightemperature superconductors: some practical considerations," Supercond. Sci. Tech., vol. 3, no. 7, 1990, 381-388.

[27] A. Cansiz, "Correlation between free oscillation frequency and stiffness in high temperature superconducting bearings," Phy. C, vol. 390, no.4, July, 2003, 356-362.

[28] A. N. Terentiev, A. A. Kuznetsov, "Drift of levitated YBCO superconductor induced by both a variable magnetic field and a vibration," Phy. C, vol.195, no. 1, May 1992, 41-46.

[29] A. N. Terentiev, H. J. Lee, C. J. Kim, et al, "Identification of magnet and superconductor contributions to the ac loss in a magnet-superconductor levitation system,” Phy. C, vol.290, no.3-4, Nov. 1997, 291-296.

[30] A. N. Terentiev, J. R. Hull, L. E. D. Long, "Flux line depinning in a magnet-superconductor levitation system,” Phy. C, vol.341-348, Nov. 2000, 1289-1290.

[31] T. A. Coombs, A. M. Campbell, "Gap decay in superconducting magnetic bearings under the influence of vibrations," Phy. C, vol.256, no.3, Jan. 1996, 298-302.

[32] H. Teshima, M. Tanaka, K. Miyamoto, et al, "Vibrational properties in superconducting levitation using melt-processed $\mathrm{YBaCuO}$ bulk superconductors,” Phy. C Supercond., vol.256, no.1, Jan. 1996, 142-148.

[33] Cansiz A., Hull J. R., Gundogdu O., "Translational and rotational dynamic analysis of a superconducting levitation system," Supercond. Sci. Tech., vol. 18, no. 7, 2005, 990-996. 
[34] T. Hikihara, T. Fujinami, F. C. Moon, "Bifurcation and multifractal vibration in dynamics of a high-Tc superconducting levitation system," Phy. Lett. A, vol.231, no.3, July 1997, 217-223.

[35] P. J. Zhuo, Z. X. Zhang, X. F. Gou, "Chaotic Motion of a Magnet Levitated Over a Superconductor,” IEEE Trans. Appl. Supercond., vol.26, no.2, Jan. 2016, Art. no. 3600406.

[36] J. Li, J. Zheng, H. Huang, et al, "Motion stability of the magnetic levitation and suspension with $\mathrm{YBa}_{2} \mathrm{Cu}_{3} \mathrm{O}_{7-\mathrm{x}}$ high-Tc superconducting bulks and NdFeB magnets," J. Appl. Phy., vol.122, no.15, Oct. 2017, Art. no. 153902.

[37] Z. Deng, J. Zheng, H. Song, et al, "Free Vibration of the High Temperature Superconducting Maglev Vehicle Model," IEEE Trans. Appl. Supercond., vol.17, no.2, July 2007, 2071-2074.

[38] J. Zheng, Z. Deng, L. Wang, et al, "Stability of the Maglev Vehicle Model Using Bulk High Tc Superconductors at Low Speed,” IEEE Trans. Appl. Supercond., vol.17, no.2, July 2007, 2103-2106.

[39] G. T. Ma, J. S. Wang, Q. X. Lin, et al, "Lateral restorable characteristics of the high- Tc, superconducting maglev vehicle above the permanent magnet guideway,” Phy. C Supercond.,vol.469, no.21, Nov. 2009, 19541957.

[40] X. J. Zheng, X. F. Gou, Y. H. Zhou, "Influence of flux creep on dynamic behavior of magnetic levitation systems with a high-Tc superconductor," IEEE Trans. Appl. Supercond., vol.15, no.3, Sept. 2005, 3856-3863.

[41] X. F. Gou, X. J. Zheng, Y. H. Zhou, "Drift of Levitated/Suspended Body in High- Tc Superconducting Levitation Systems Under Vibration-Part I: A Criterion Based on Magnetic Force-Gap Relation for Gap Varying with Time,” IEEE Trans. Appl. Supercond., vol.17, no.3, Sept. 2007, 3795-3802.

[42] X. F. Gou, X. J. Zheng, Y. H. Zhou, "Drift of Levitated/Suspended Body in High- Tc Superconducting Levitation Systems Under Vibration-Part II: A Criterion Based on Magnetic Force-Gap Relation for Gap Varying with Time,” IEEE Trans. Appl. Supercond., vol.17, no.3, Sept. 2007, 3803-3808.

[43] L. Alloui, K. B. Alia, F. Bouillault, et al, "Numerical study of the relation between the thermal effect and the stability of the levitation system excited by an external source," Phy. C Supercond., vol.487, no.4, April 2013, 1-10.

[44] C. G. Huang, C. Xue, H. D. Yong, et al, "Modeling dynamic behavior of superconducting maglev systems under external disturbances,” J. Appl. Phy., vol.122, Aug. 2017, Art. no. 083904.

[45] C, G. Huang, B. Xu, Y. H. Zhou, "Dynamic simulations of actual superconducting maglev systems considering thermal and rotational effects," Supercond. Sci. Tech., vol.32, no.4, Feb. 2019, Art. no. 045002.

[46] F. Sass,G. G. Sptelo, R. D. Andrade, et al, "H-formulation for simulating levitation forces acting on HTS bulks and stacks of 2G coated conductors,” Supercond. Sci. Tech., vol.28, no.12, Nov. 2015, Art. no. 125012.

[47] L. Quéval, K. Liu, W J Yang, et al, "Superconducting Magnetic Bearings Simulation using an H-formulation Finite Element Model," Supercond. Sci. Tech., vol.31, no.8, June 2018, Art. no. 084001.

[48] R. Brambilla, F. Grilli, L. Martini, "Development of an edge-element model for AC loss computation of high-temperature superconductors," Supercond. Sci. Tech., vol.20, no.1, Nov. 2007, 16-24.

[49] J. Sheng, M. Zhang, Y. Wang, et al, "A new ring-shape high-temperature superconducting trapped-field magnet," Supercond. Sci. Tech., vol.30, no.2, Aug. 2017, Art. no. 094002.

[50] V. M. R. Zermeno, A. B. Abrahamsen, N. Mijatovic N, et al, “Calculation of alternating current losses in stacks and coils made of second generation high temperature superconducting tapes for large scale applications," $J$. Appl. Phy., vol.114, no,17, Nov. 2013, Art. no. 014023.

[51] M. M. R. Zermeno, F. Grilli, "3D modeling and simulation of 2G HTS stacks and coils,” Supercond. Sci. Tech., vol.27, no.4, March 2014, Art. no. 044025.

[52] G. Francesco, "Numerical modeling of HTS applications," IEEE Trans. Appl. Supercond., vol.26, no.3, 2016, Art. no. 0500408.

[53] T. Gong, Y. Peng, C. Ye, et al, "Towards Faster FEM Simulation of Thermo-Electromagnetic Properties of HTS Bulk in Travelling Magnetic Fields Using a Novel Approach,” J. Low Temp. Phy., vol.39, no.3, June 2017, 50-55(in Chinese).

[54] D. Varshney, K. K. Choudhary, R. K. Singh, "Analysis of in-plane thermal conductivity anomalies in $\mathrm{YBa}_{2} \mathrm{Cu}_{3} \mathrm{O}_{7}$ cuprate superconductors," New J. Phy., vol.5, no,1, June 2003, 72.1-72.17.

[55] J. R. Hull, A. Cansiz, "Vertical and lateral forces between a permanent magnet and a high-temperature superconductor," J. Appl. Phy., vol.86, no.11, Aug. 1999, 6396-6404.
[56] K. Liu, W. Yang, G. Ma, et al, "Experiment and simulation of superconducting magnetic levitation with REBCO coated conductor stacks," Supercond. Sci. Tech., vol.31, no.1, Dec. 2018, Art. no. 015013.

[57] K. Liu, G. Ma, C. Ye, et al, "Experimental Studies on the Dynamic Responses of Coated Superconductor Stack Levitated Above a Permanent Magnet Guideway," IEEE Trans. Appl. Supercond., vol.28, no.3, Jan. 2018, Art. no. 3600305.

[58] M. Tsuda, T. Kojima, T. Yagai, et al, "Vibration Characteristics in Magnetic Levitation Type Seismic Isolation Device Composed of Multiple HTS Bulks and Permanent Magnets," IEEE Trans. Appl. Supercond., vol.17, no.2, July 2007, 2059-2062.

[59] Z. Q. Zhu, D. Howe, "Halbach permanent magnet machines and applications: a review," IEE Proceed.-Electric Power. Appl., vol.148, no.4, July 2001, 299-308.

[60] R. Sun, J. Zheng, B. Zheng, et al, "Study on the Magnetic Field Inhomogeneity of a Halbach Permanent-Magnet Guideway Due to Different Defects,” IEEE Trans. Appl. Supercond., vol.26, no.1, Nov. 2016, Art. no. 3600107.

[61] G. T. Ma, Q. X. Lin, J. S. Wang, et al, "Method to reduce levitation force decay of the bulk HTSC above the NdFeB guideway due to lateral movement,” Supercond. Sci. Tech., vol.21, no.6, 2008, Art. no. 065020.

[62] J. C. Wang, G. Q. Jiang, Y. Y. Xu, et al, "Relaxation characteristic of the levitation force of bulk-type Y-Ba-Cu-O with pre-loading applied,” Cryo. \& Supercond., vol.39, no.7, 2011, 47-52(in Chinese).

[63] Y. Iwasa, et al, " Case studies in superconducting magnets design and operational Issues,” 2nd ed. New York: Springer; 2009. 